AGRARIS: Journal of Agribusiness and Rural Development Research

Vol. 6 No. 1 January-June 2020

Article History:

Submitted : June $16^{\text {th }}, 2020$

Accepted : August $5^{\text {th }}, 2020$

\title{
Economic Intuition to Social Capital: Household Evidence from Jimma Zone, South-West Ethiopia
}

\author{
DOI: https://doi.org/10.18196/agr.6192
}

\begin{abstract}
The notion of social capital is noble in social science literatures and recently getting noteworthy attention in economics. Its economic relevance has also been well documentedin empirical studies. In this paper, we established relationshipsbetween the stock of household social capital and annual net income following approach for binary logit. Besides, we examined the relative economic importance of general viz special stocks of social capital. Statistical requirements with logistic regression were all tested robust. Consequently, the effectof social capital stock on household economy has found substantial. Of the two distinct forms, the special facet of social capital was found better and significant contributor to householdeconomy. However,the general aspect was suggested insignificantasit was not meaningfully interpreted in the household economic network.Thus, a wise household need to appropriate the general to special social capital establishment, since every additional stock of the later could be meant to considerablyhelp own welfare.
\end{abstract}

Keywords: Household Economy, Jimma Zone, Logistic analysis, Social Capital Stock

\section{INTRODUCTION}

Despite its multifaceted insinuation to nations' socioeconomic development, the topic of social capital has given trifling attention in economics. Without upheld social capital, it's hard to think of developments in the rest of the economy as institutional quality is a priori.A growingnumber of studiesdivulgean essentiallink between social capital measures and several indicators of economic outcomes. Wickramasuriya et al. (2011) well-thought-out social capital a moment they found significant role of civic engagement and enhanced personal networks in their household level analysis from Central Province of Sri Lanka. We need to be clear that, the idea of social capital, here, constitute personal, or either, engagements in civic organizations and established inter/and-intra-personal interconnections. Obviously, both could serve a promising part of societal networks in a meaningful manner.Coleman (1999) has defined 'social capital' as a multiplicity of various entities, having two mutual elements; all consisting of some feature of social buildings. According to him, these mutual elements ease certain activities of individuals belonging in the structure through connections of trust, interchange and interactions. Bowles and Gintis (2002) referred 'trust, individual's concern 
one another, individual's willingness to be governed by norms and cultures of general community, and one's commitment to punish otherswho malfeasance the established norm". Today, it is decisively rooted in economics and other social science disciplines. The term 'social capital' has lately linked more to human network and relational lives rather than social norms. For example (Stiglitz, 1999; Paldam, 2000; Dasgupta, 2005; Sobel, 2002) defined the term 'social capital' as a collection of social relations. Social networks undoubtedly entail several investment and even sacrifice in the form of money, time, prestige and information in a manner that could group access to better income, social life, knowledge and other benefits (Uphoff, 1999; Stiglitz, 1999; Dasgupta, 2005). Some networks impede free of cost; naturally you were born default within certain relations whether you like it or not. These types of networks normally are known as general relations. However, other forms of relationships can be established through a costly process, and they often have meaningful interpretation in life. In literature, the later forms are known as special relations (Bowles and Gintis, 2002; Dasgupta, 2005; Putnam, 1995; Ferragina, 2010).

An economic role of social capital is well documented in social science and economic literatures. In their national-wise survey Knack and Keefer (1997) has, in turn, shown that a unit measure scale advance in state level trust could result in a more than three-fold improvement of economic growth. Theevidenceshows actuality of large response from aggregate economy with respect to changes in national stock of social capital. In this paper we are not going through a more advanced model for social capital since it is limited to microlevel analysis. We rather rely on simple definition of social capital emphasizing norms, institutions and conventions. Avoiding complexities, we consider individuals' civic engagement dummy and personal interrelationships to satisfy the definition of social capitaldue to(Miller, 2003; Greene and Brown, 1997; Becker, 1964; Mencer, 1974; Woolcock, 1998; Schuller et al., 2000; Coleman, 1988).

Empiricalevidences on the relations between social capital and economic outcomes have clear theoretical foundation. Yasunobu and Bhandari (2009) demonstrate the positive role of social capital on economic growth since social ties intensify efficiency across beneficiary group. With enhanced cooperation and civic engagement, it is likely that both production and distribution costs could decrease.Sincemarketing information is now expected to be availed easily, transaction costs would also vanish. Moreover, effective team work is supposed to enhance innovation as well as exchanges of knowledge across units. All this effects from social capital is acknowledged to enhance productivity and growth at the same time (Fudenberg and Maskin, 1986; Yasunobu and Bhandari, 2009).

The Organization for Economic and Cultural Development (OECD) demonstrate the positive aspect of social capital on economic growth through potential efficiency that can be realized from societal cooperation (OECD, 2013). This part of demonstration bases on the fact that, the networks of norms swift trust and ensure collaboration. Theoretically sound is to assume operational efficiency, and hence growth, that could result from enhanced networks and cooperation. This paper also lays its analysis on this theoretical foundation regarding the topic we are dealing with. 
We survey a random draw of households from various formations of Jimma zonal state administration. It, in the first place, is initiated to lesson whether or not household stock of social capital has to do with own economic status. Thus, our survey should be understood as micro-unit analysis unlike to most literatures discussed herewith so far. We toughlyvalue clear setting form lower segment of the economy as it serves building block in an entire sectorial formation. The study is aimed to examine the effect of households' stock of social capital on their economic performance. Besides we also aim to examine the relative importance of general and special social capital stock in explaining the trend of economic growth using household data from Jimma zone. The study covers cross-section of about 383 units for 2018/2019.

\section{METHODOLOGY}

\section{Study Area}

This household survey was confined to Jimma Zone of Oromia regional state, situated at the South-west of Ethiopia (Figure 1). According to Jimma zone Finance and Economic Development office report (2016), Jimma zone is composed of 21 sub-administrative units called woreda.According to the same report, the total population of Jimma zone was estimated over three million under 512,506 households. The climatic condition of Jimma zone is characterizedby $15 \%$ highland, 67\% midlands and about 18\% lowlands (UNDP, 2000). Jimma is amongthe major coffee growing regions in the country. The areaconsistently receives good rain, ranging from 1200-2800 mm per annum.Therefore, this gives an opportunity to invest in agri-business and grantees the feasibility of these projects in particular. Besides, Jimma city serves as the largest market center in South-West Ethiopia.With easy access to transportation and other necessities, Jimma serves adequate marketcenter for potential investments in and around its geographical boundary. It has latitude and longitude of about $7^{\circ} 40^{\prime} \mathrm{N}$ and $36^{\circ} 50^{\prime} \mathrm{E}$, respectively. Jimma is characterized to exhibit tropical rainforest climate as ofthe Köppen climate classification. Temperatureat Jimma ranges between $20^{\circ} \mathrm{C}$ and $25^{\circ} \mathrm{C}$ year-round range, on daily average (Lewis, 2014). Below is an official map of Jimma Zone (UNDP, 2000).

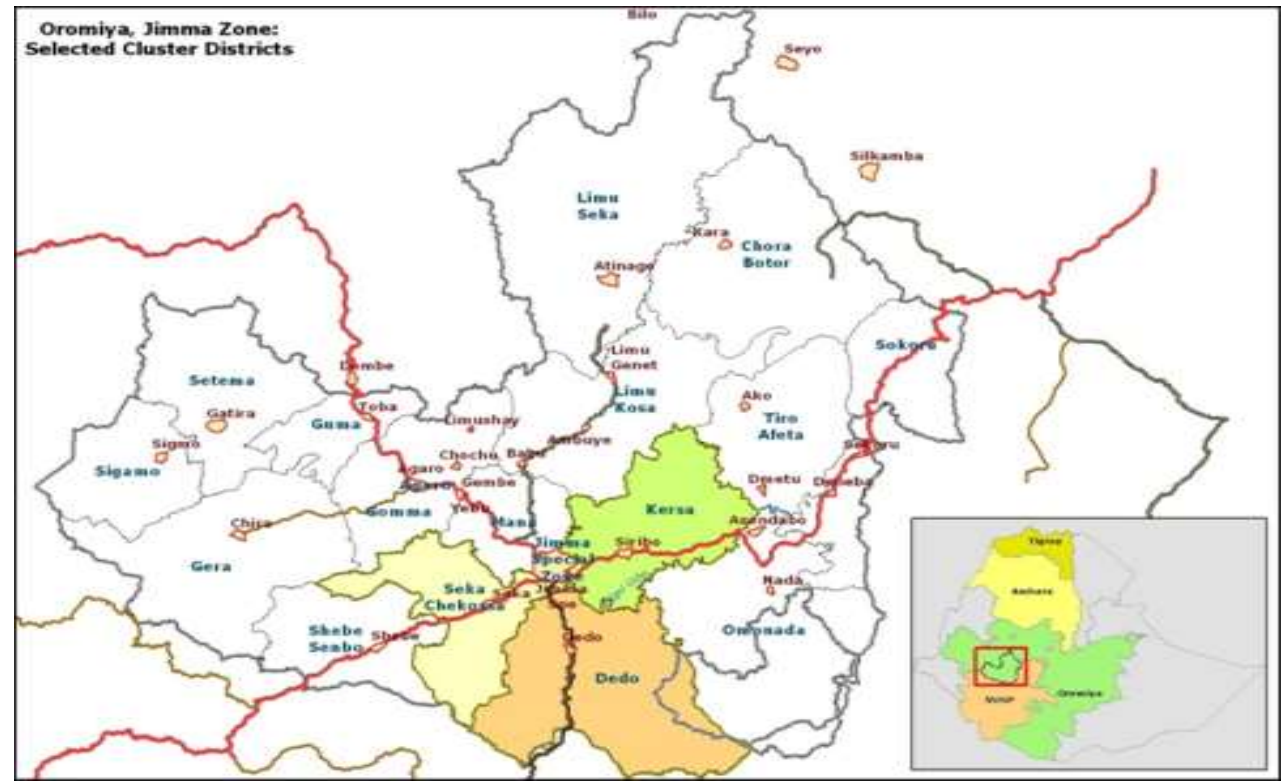

FIGURE 1. AN OFFICIAL MAP OF JIMMA ZONE (UNDP, 2000) 


\section{Data Type and Source}

This study is based on both quantitative and qualitative data forms. The quantitative element was directly obtained from therespondents. Informations related to infrastructure access, distances from nearest market place, total annual production, total annual expenditure and income levels, household sizes and other relevant measures were collected directly from the included respondents. Supportive data such as Zonal marketing report, statistical reports from Central Statistical Agency, Rural Development Bureau of Jimma zone and various woreda level offices were also used as our secondary sources.Qualitative information related to the specific channels through which social capitals affect households' economic outcomes were also obtained from the individual respondents included for the purpose of our survey.

Since the study was based on information both from primary and secondary sources, family-centric informations such as; social capital endowment and economic position, were collectedthrough structured questionnaires. Data on previous commodity price as well as production levels were used from the records of Jimma zone trade and Industry Department to supplement our secondary information needs.

\section{Study Population and the Sample}

The rural households from Jimma zone are the target groups with the present survey. We move through various stages to arrive at the final unit included in the analysis. We have started by arbitrarily selecting four out of twenty one woredasmaking up Jimma zone. These include; Limmu-Kossa, Sokoru, Manna and Gommaworedas. Again, each selected woreda was sub-divided in various sub-administrative units called Kebele, and required number of kebele was randomly selected from each of the four woredas. Finally, proportional size across sampleworeda was arbitrarilytaken from respectivekebele administrations.

According to official reports of respective woreda administration, household size across each of the four woreda were reported to be, 25,305 for Limu Kossa; 30,115 for Sokoru; 18,201 for Manna; and 21,449 for Gomma. Thetotal sum of households in four districts is equals 95,070. Due to(Noelet al., 2012), the sample size selected from the four districts was 383 (equation 1).

$$
n \geq \frac{N}{1+(N-1)\left(\frac{2 d}{z}\right) 2} \text {. }
$$

Where $\mathrm{N}$ stands for total population; $\mathrm{n}$ represents sample size; $(\mathrm{d}=0.05)$ is margin of error; and $(\mathrm{z}=1.96)$ for a 95 per cent confidence interval.

The required sample size was proportionally distributed across each sample woreda as follows;

* Limu Kossa: $\frac{383}{95,070}$ x 25,305 = 102 households

* Sokoru: $\frac{383}{95,070} \times 30,115=121$ households

* Manna: $\frac{383}{95,070} \times 18,201=74$ households

* Gomma: $\frac{383}{95,070}$ x 21,449= 86 households 


\section{Data Analysis}

We rely both on descriptive and inferential statistical tools to analyze the data.Descriptive tools indicating themaximum and minimum values as well as mean and standard deviation of various measures were used. Besides, binomial logit regression was employed to estimate the impact of a household total stock of social capital on economic performance. Hence, the latter replicates the inferential aspect.

\section{Measurement of Social Capital: Household Level}

In this paper we contend that,social network is a vital element of social capital. Social capital may be defined as stock of social relationships that an individual person possesses (Ferragina, 2010; Putnam, 1995). Individuals can form relations with others in different ways. Hence, social relations can be grouped as general and special social.General relations are typically congenitalfromgenetic factors. An important feature of such relationships is that they are established and are already there for you whether you like it or not. As far as they are establishedgenetically, you will have no contribution in your share the general aspect of social capital. Besides, at their work place individuals could interact with peer as well as their bosses by default. In this case, general relation is already around whether/or not a worker likes. Relationsestablished externally without individual effort are features of general social capital (Wickramasuriya et al, 2011; Akcomak, 2008; Knowles, 2005).

Sometimes any one member of a given family may give special trust to another member, which he cannot share with the rest in the family. A member withsuch special respect and trust from a group is said to have special capital on relative terms. Similarly, from a class of say, sixty or more, one or two may have close relation and communication to the school director, not all. Obviously, those with better relation to their director will have better access to some key school facilities or, even personal contribution from the director. Turning back to our point, special aspect of social capital begins from recognition of such seemingly small but significant interpersonal relations between individuals. A boss my not treat all staff members equally; he may share only functional roles with all, but core issues can be communicated to some with relatively better personal quality. The special aspect of social relation gives better trust and certainty than the already established general relation. To clarify the difference among the two, general social relations are large in size but shallow in depth; while the special aspects are in converse (Wickramasuriya et al, 2011; Shufang and Yan, 2010; Thokozani, 2012).

To simplify things, the general relation based on blood is limited to family membership; i.e., sharing the same mother or father or either. Based on (Saidov, 2017; Miller, 2003;OECD, 2009; Shufang and Yan, 2010; Ponthieux, 2004)general aspect of social capitalhas been measured by; (a) Number of people a household possess relation to; and (b) Engagement in civic organization. We used 'Idir' as a local formation to proxy the civic engagement in the local sense. Following (UN, 2005; Thokozani, 2012; Wickramasuriya et al, 2011) we capture the special component of social capital guided by whether one is quite sure that he or she has, at least, one person in life that he or she will not leave him or her during difficulties in all life events; good or bad, long lived or short lived. In the same passion above, 
sum total of the two components form a household's total social capital stock (TSSC). Stated differently, the social capital can be split into two as general and social capital stock; for an ith individual respondent.

With this conceptualization, a households' total stock of social capital (TSSC) is, thus, the sum total of general social capital (GSC) and Special Social Capital (SSC). It follows that;

TSSC $i=$ GSC $i+$ SSC $i$

\section{Measuring Household Economic Wellbeing}

With regard to household economic wellness, we used the individual household annual income and expenditure accounting based on (Sharma et al., 2012). The wellbeing analysis refers to whether a household is able to cover personal livelihood without being indebted each year. In this conception, if a household has never borrowed for family consumption during the survey period then that household is economically safe. Todetermine each household current net income, we have systematically collected information on past year production, sale, consumption, and expenditure (in terms of ETH) item by item throughout the year. A difficulty with our approach was that some products were nonmarketable; and some others were notsold in the same year, difficulty to have their money value. A notable difficulty arises from the fact that, considerable proportion of rural production is allotted for family consumption and that; a proportion couldn't sell in the same year they are produced. Efforts were made to come-up with handling mechanisms: productions at hand are monetized at respective current market price. Henceforward, an aggregate of annual spending has been withheld from gross income obtained in that year. The difference account for the periodic economic position of each household surveyed. Then, total expenditure was deducted total income earned during the year.

$$
\mathrm{NETi}=\mathrm{INCi}-\mathrm{EXPi}
$$

Where,NETstands for net income of ith household; INCi and EXPi, respectively, are the annual income and expenditures of household i.Since the household being economically secure is the response variable in logit specification, we need to define it clearly. Whether or not a household is economically safe is categorical in two layers. The response variable assumesa 1 value if a household under consideration is economically secure; and 0 otherwise. Finally, the responsevariable can be defined as follows;

\section{Binary Logistic Regression}

$$
E \cdot S E C_{i}=\left\{\begin{array}{l}
1, \text { if a household is secure } \\
0, \text { otherwise }
\end{array}\right\} .
$$

We model the actual effect of social capital on household economy via the approach for binary logistic analysis. Households' economy is a response variable in the logit specification. If the computed net income for a household is positive, corresponding income dummy takes on a value 1 ; and zero otherwise. The specification is based on the notion that, with positive net income a household is able to cover currentconsumption expenditure without being indebted.

An outcome variable $y_{i}$ follows a Bernoulli distributiontaking 1 (occurrence) with probability of success $P_{i}$ or 0 with probability of failure $1-P_{i}$ in the logistic regression 
framework. In this paper logit was specified letting $y(n \times 1)$ bea dichotomous with classes 1 (economic security) and 0 (no economic security).

Due to (Maddala, 1998; Wooldridge, 2013), the vectors of predictors ( $x$ ) and outcome variable $(y)$ can be developed as shown below:

SEM is also a stronger hybrid technique in terms of confirmatory aspects of factor analysis, path analysis and regression or considered as having interaction modeling, nonlinearity, correlated independent variables (Narimawati \& Sarwono, 2017).

$X=\left(\begin{array}{cccc}1 & x_{11} & \ldots & x_{1 k} \\ 1 & x_{21} & \ldots & x_{2 k} \\ \vdots & \vdots & \ddots & \vdots \\ 1 & x_{n 1} & \ldots & x_{n k}\end{array}\right) Y=\left(\begin{array}{c}y_{1} \\ y_{2} \\ \vdots \\ y_{n}\end{array}\right) \beta=\left(\begin{array}{c}\beta_{0} \\ \beta_{1} \\ \vdots \\ \beta_{k}\end{array}\right) \sim(k+1) \times 1$

Where $X$ is vector of regressors; $Y$ is a column vector of an outcome variable; $\beta$ represents the vector of parameters. FollowingGujarati (2004), the probability that a household is economically secure for known values of each regressor considered is given by;

$$
P_{i}=1 / 1+\mathrm{e}^{-Z_{\mathrm{i}}}
$$

Where $Z_{i}=\beta_{0}+\beta_{i} X_{i} ; \quad P_{i}$ is a conditional probability that the $i^{\text {th }}$ household is economically secure for the known values of each regressor in the model; $\beta_{0}$ is a constant; $\beta_{i}$ are slope coefficients; and, $e$ is base of natural logarithm. For mathematical treatmentsfor negative exponents, (equation 5) can be re-expressed as follows;

$$
P_{i}=\frac{e^{z_{i}}}{1+e^{z_{i}}}
$$

On the other hand, a probability that a household is economically insecure equals the value leftover of equation (6) is deducted from unity;

$$
1-P_{i}=\frac{1}{1+e^{Z i}}
$$

The odds ratio in favor of a household to be economically secure is given by the ratio of the two probabilities.

$$
P_{i} / 1-P_{i} \Rightarrow \frac{e^{Z i}}{1+e^{Z i}} / \frac{1}{1+e^{Z i}}=e^{Z i}
$$

The natural $\log$ of equation (8) gives the below final expression;

$$
L=\ln \left(P_{i} / 1-P_{i}\right)=\ln \left(e^{Z i}\right) \Rightarrow \beta_{i}+\beta_{i} X_{i}+U_{i}
$$

Where $L=\log$ of odds ratio and $u_{\mathrm{i}}$ is the error term. Based on equation (9) we model the following final relation between the dependent and independent variables of this study.

$$
L=\beta_{0}+\beta_{1} \text { TSSC }_{i}+\beta_{2} I_{D I R}+\beta_{3} \text { EDUC }_{i}+\beta_{4} \mathrm{AGE}_{i}+u_{i} \ldots
$$

Where TSSC is Total Stock of Social Capital of householdi;EDUCis Education level of the respondent $i$ measured in years of schooling; AGE is the age in years of the $i^{\text {th }}$ household head; and IDIRisa dummy taking a value of 1 if a respondent is member of its community 'Idir'; and 0 , if not a member. 


\section{Diagnostic Test}

Once the model is fitted, we would be interested to know how effective the model is in explaining the outcome variable.

\section{a. Pearson Chi-Square Test}

The Pearson $\chi^{2}$ statistic is based on observed $(O)$ and expected $(e)$ observations.

$$
\chi^{2}=\sum_{i=1}^{n} \frac{(O-e)^{2}}{O}=\sum_{i=1}^{n} \frac{\left(y_{i}-n_{i} \hat{p}_{i}\right)^{2}}{n_{i} \hat{p}_{i}\left(1-\hat{p}_{i}\right)}
$$

Where $y_{i}$ is the observed value of $Y$; $\hat{p}_{i}$ is fitted $Y$ for a given value of $x_{i} ; n_{i}$ is the number of observations. Large Pearson chi-square for a given regressor indicates that there is strong association between each of independent and the dependent variables keeping the effect of the other factors constant. Here we test the null hypothesis of $H_{0}$ :there is no association between variables against its alternative $H_{1}$ : there is association between the dependent and particular independent variable describing the outcome variable.

\section{b. Wald Test}

A Wald test is used to test the statistical significance of each coefficient $(\beta)$ in the model. If the Wald test is significant for a particular explanatory variable, then we would conclude that the parameter associated with the variable is not zero so that the variable should be included in the model; otherwise it should be omitted from the model (Agresti, 1996). We test the null $H_{0}: \beta_{\mathrm{j}}=0$ against the alternative $H_{1}: \beta_{\mathrm{j}} \neq 0$ in the Wald test. The Wald test statistic (Z) for this hypothesis is

$$
Z^{2}=\frac{\hat{\beta}_{j}^{2}}{\operatorname{var}\left(\hat{\beta}_{j}\right)} \sim \chi^{2}(1)
$$

Where $\hat{\beta}_{j}$ is the estimated regression coefficient and $\operatorname{var}\left(\hat{\beta}_{j}\right)$ is the variance of $\hat{\beta}_{j}$.

\section{c. The Likelihood Ratio Test}

The likelihood ratio test statistic $\left(G^{2}\right)$ is the test statistic commonly used for assessing the overall fit of the logistic regression model. The LL ratio is computed based on $-2 L L(-2$ times log likelihood). The likelihood ratio statistic is obtained by subtracting the two times log likelihood ( $-2 L L)$ for the full model from the log likelihood for the intercept only model. This log likelihood-ratio test uses the ratio of the maximized value of the likelihood function for the intercept only model $L_{0}$ over the maximized value of the likelihood function for the full model $L_{1}$. The likelihood test statistic is given by:

$$
G^{2}=-2 \log \left(\frac{L_{0}}{L_{1}}\right)=-2\left[\log \left(L_{0}\right)-\log \left(L_{1}\right)\right]=-2\left[L L_{0}-\left(-L L_{1}\right)\right]
$$

Where, $L L_{0}$ represents the log likelihood value of the model which has the intercept term only and $L L_{1}$ is the log likelihood value of the full model. The likelihood ratio statistic 
has a chi-square distribution and it tests the null hypothesis that all logistic regression coefficients except the constant are zero. The degrees of freedom are obtained by differencing the number of parameters in both models. It is compared with chi-square value at the difference between degree of freedom of both models. The p-value less than 5 percent level of significance lead to the rejection of the null hypothesis thereby implying that all the predictor effects are zero. When the likelihood test is significant, at least one of the predictors is significantly related to the response variable (Hosmer and Lemeshow, 2000).

\section{d. Hosmer-Lemeshow Test}

The Hosmer-Lemeshow test is used to check the overall model fit. In this approach, data are divided into ten groups. From each group, the observed and expected numbers of events are computed. Then, the Hosmer-Lemeshow test statistic is given by:

$$
\hat{C}=\frac{\sum_{j}^{g}\left(O_{j}-E_{j}\right)^{2}}{V_{j}}
$$

Where $E_{j=} n p_{j}$; g is the number of groups; ${ }^{O_{j}}$ is observed number of events in the $\mathrm{j}^{\text {th }}$ group; $E_{j}$ is expected number of events in the $\mathrm{j}^{\text {th }}$ group and $V_{j}$ is a variance correction factor for the $\mathrm{j}^{\text {th }}$ group.If the observed number of events differs from what is expected by the model, the statistic $\hat{C}$ will be large and there will be evidence against the null hypothesis that the model is adequate to fit the data. This statistic has an approximate chi-square distribution with ( $\mathrm{g}-2)$ degrees of freedom (Agresti, 1996).

\section{e. Other Tests}

In logistic regression, outliers are observations whose values deviate from the expected range and produce extremely large residuals. These outliers can unduly influence the results of the analysis and lead to incorrect inferences. An observation is said to be influential if removing the observation substantially changes the estimate of coefficients. Influence can be thought of as the product of leverage and outliers. An observation with an extreme value on a predictor variable is called a point with high leverage. Leverage is a measure of how far an independent variable deviates from its mean. In fact, the leverage indicates the geometric extremeness of an observation in the multi-dimensional covariate space. These leverage points can have an unusually large effect on the estimate of logistic regression coefficients (Cook, 1998). Using the following rules it is possible to identify if an observation is outlier or influential:

$\checkmark$ Residuals: Standardized, Standard, deviance and Pearson residuals are obtained using different software. Observations with values larger than three in absolute values are considered as outliers (Agresti, 2007).

$\checkmark$ DFBETAS:Measure of how much an observation has affected the estimate of a regression coefficient (there is one DFBETA for each regression coefficient, including the intercept). 
Cook's D:It measures an averageeffect on the group of regression coefficients, as well as the group of fitted values. In logistic regression, a case is identified as influential if its Cook's distance is greater than one (Hosmer- Lemeshow, 2000).

\section{RESULT AND DISCUSSIONS}

\section{Descriptive Information}

\section{Household Socio-Demographic Characteristics}

A sample of 383 households from Jimma zone was arbitrarilytaken to address the objectives of this study. We have collected information on various issues; like, the demographic characteristics, socio-economic and political conditions describing ourtarget group. The family size and age distribution across our sample was presented in table (1).

TABLE I. FAMILY SIZE AND AGE DISTRIBUTION OF THE SAMPLE HOUSEHOLDS

\begin{tabular}{lccccc}
\hline Variable & Obs. & Mean & Std.Dev. & Min & Max \\
\hline Age & 383 & 35.6 & 6.9196 & 19 & 56 \\
Family Size & 383 & 4 & 0.8514 & 1 & 8 \\
\hline Soure: (Own Sur 2018$)$ & & &
\end{tabular}

Source: (Own Survey, 2018)

Evident from table (1) is high age variability with standard deviation of about 6.92. The range of the age variable equals 37 with minimum and maximum 19 and 56 years, respectively. Therefore, we can say that the study has considered the sections of the society at various stages; hence, that could further guarantee the reliability of our analysis results thereby simultaneously avoiding biases arising from concentration of the sample on either extreme of the age group. Besides, the mean age is about 35 years and 6 months showing that majority of the study population were young.

The mean size of family was estimated around four with standard deviation of 0.8514 thereby signifying less variability in size distribution. This result may also imply that, any social, economic and political differences across households resulting from differences in family size cannot be an issue with us. As far as the family size distribution was symmetric, the multidimensional welfare differences among individual households because of differences in size might not be important. The mean family size is four; while the minimum and maximum sizes are 1 and 8 , respectively.

Table (2) reports the religion and gender backgrounds of the households included in the current analysis. Thedata on the sex and religion variables belongs to the household heads. It should be noted that, the religion of household head belongs also to every member of the family.

The framework of the corn farmers' performance behavior model, especially farmers' cooperatives, as a liaison between agro-food supply chains of small-scale producers and sustainable institutions for gaining more added values, is determined by the farmers' characteristics. The participants were mostly 40 to 45 years old; their ethnic is java. They had been married for more than 20 until 25 years, they had 4 family members, their education background is 9 years, and most of them had 2-10 year farming experience. 
TABLE 2. RELIGION AND SEX DISTRIBUTION OF THE SAMPLE RESPONDENTS

\begin{tabular}{llrrr}
\hline & & Frequency & Percentage & Cum. Pert. \\
\hline Sex category & Male & 103 & 26.89 & 26.89 \\
& Female & 280 & 73.11 & 100 \\
& Gross & 383 & 100 & 33.16 \\
Religion Category & Muslim & 127 & 33.16 & 54.05 \\
& Orthodox & 80 & 20.89 & 85.90 \\
& Protestant & 122 & 31.85 & 100 \\
& Wake feta & 54 & 14.10 & \\
& Gross & 383 & 100 & \\
\hline
\end{tabular}

Source: (0wn Survey, 2018)

As it can be observed from table (2), out of 383 total respondents, only 26.89 per cent (103) of the total response rate are male; while the remaining 73.11 per cent (280 out of 383) belongs to female counterparts. That means about 73.11 per cent of the household was femaleheaded. Hence, most of the household decision in the study areawas made by females.

Table (2) also reveals that majority of the respondents were followers of Islam accounting for about 33.16 percent of the total response rate. The second dominant religion was Protestantism representing about 31.85 percent of the total response rate. 122 out of 383 total respondents are Protestants. Besides, about 80 (20.89\%) individuals were reported to follow Orthodox Christianity; while, the remaining 14.10 percent of the total response rate belong to Wake feta. There is no such large group variabilityregarding religion distribution between Islam and Protestantism as they both account for almost equal proportion of the total response rate. On the one hand, the proportion Wake feta fellowship wascomparativelytrifling. Therefore; Islam, Protestantism and Orthodox Christianity are widely practiced in the study area. We realizereligious heterogeneity and coexistence of diversified views was also acknowledged from Jimma zone. The proportion of various religions from Jimma zone can also be shown using simple pi-chart as displayed hereunder.

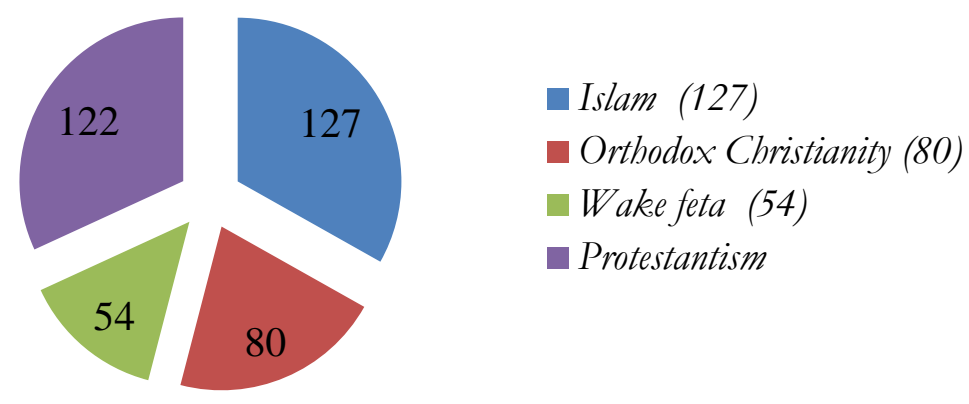

Source: (Own Survey, 2018)

\section{FIGURE 2. FREQUENCY DISTRIBUTION OF RELIGION AMONG SAMPLE RESPONDENTS}

Figure (1) is a reflection of table (2), which again indicates the dominancy of Islam followed by Protestantism, Orthodox Christianity and Wake feta respectively. 


\section{Education Level and Ethnic Composition}

Ethnic composition in Jimma zone was found to be heterogeneous thereby holding dominantly of Amhara, Dawro, Oromo and Yem ethnic groups among others. However, the area is most dominantly inhibited by the Oromo people accounting for more than half estimatedat about 56.13 percent of the total response rate. It means that, out of 383 sample respondents 215 individuals belong to Oromo ethnic group indicating the dominancyof the indigenous group. Amhara was the next dominant group thereby accounting for about 24.02 percent of the total response rate. Of the total of 383 sample respondents, 92 belong to the Amhara ethnic group. The third largest share goes to the Yem people accounting for about 16.71 percent of the total response; while the remaining 3.39 percent of the total response rate goes to Dawro people in the general ethnic composition of the study area. More than 80 percent of the total respondents belong to only two ethnic groups of which about more than 70 percent is explained by the Oromo people. Therefore, we found the dominancy of one ethnic group in the study area revealing large variability in the distribution of ethnic group.

TABLE 3. EDUCATION AND ETHNIC COMPOSITION

\begin{tabular}{|c|c|c|c|c|}
\hline \multicolumn{2}{|c|}{ Indicators } & Frequency & Percentage & Cum. Pert. \\
\hline \multirow{5}{*}{ Ethnic Composition } & Amhara & 92 & 24.02 & 24.02 \\
\hline & Dawro & 13 & 3.39 & 27.41 \\
\hline & Oromo & 215 & 56.13 & 83.54 \\
\hline & \multirow[b]{2}{*}{ Total } & 64 & 16.71 & 100 \\
\hline & & 383 & 100 & \\
\hline & Diploma & 39 & 10.18 & 10.18 \\
\hline \multirow[t]{4}{*}{ Education Level } & \multirow{3}{*}{$\begin{array}{l}\text { Secondary Education } \\
\text { Primary Education }\end{array}$} & 104 & 27.15 & 37.33 \\
\hline & & 42 & 10.97 & 48.30 \\
\hline & & 198 & 51.70 & 100 \\
\hline & & 383 & 100 & \\
\hline
\end{tabular}

Source: (Own Survey, 2018)

We can also demonstrate the ethnicity and education level frequency of households using diagrams. Figure (2) below indicates the frequency distribution of ethnic composition as discussed above.

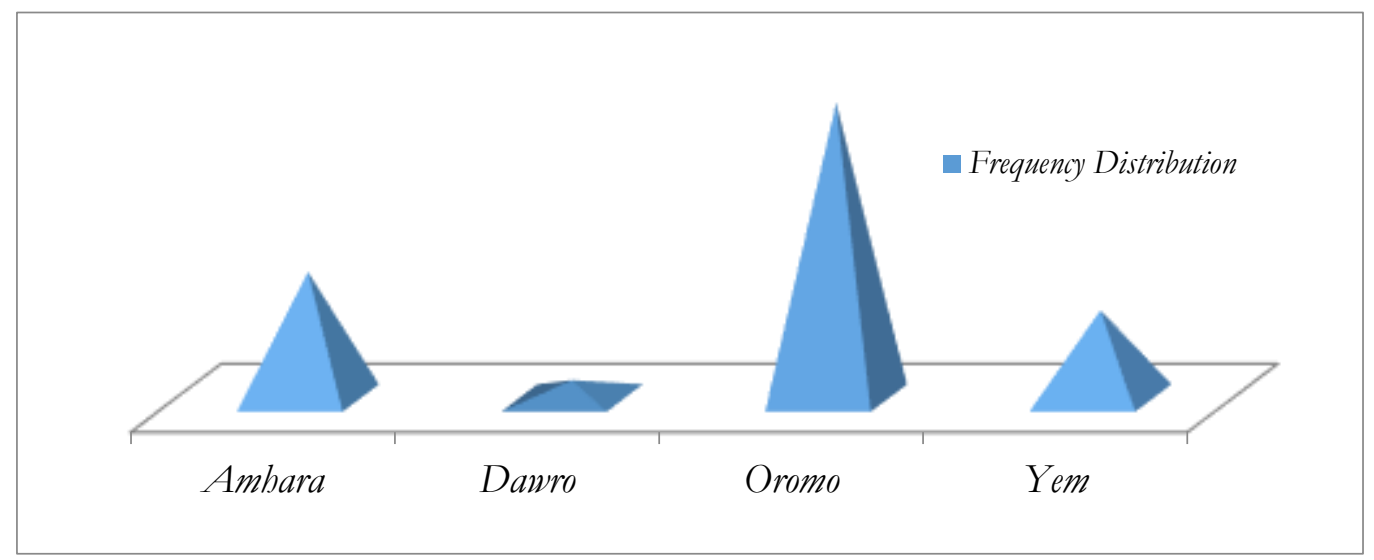

Source: (Own Survey, 2018)

FIGURE 3. FREQUENCY DISTRIBUTION OF ETHNIC COMPOSITION 
Morethan half of the total response rate is illiterate indicating the proportion of individuals who didn't attend at least basic education. There is evidence that out of 383 total respondents, 198 are illiterate exceeding half of the total sample by more than 6 individuals. A proportion of individual respondents who pursued secondary education totals 104; which is about 27 percent of the total response rate; while 42 out 383 total respondents attended primary education. Alternatively, about 11 percent of the total response rate has pursued primary education. Furthermore, a proportion of individual respondents out of the total response rate to have graduated in diploma were about 10.18 percent. Taking head count of individual respondents, it means only 39 out of 383 total respondents were diploma graduates. Considering the large size of cross sectional observation with this study this size is very small.

Generally, the frequency distribution analysis of education indicates that majority, more than half of the total response rate was illiterate. This indicates, most of household consumption, investment and marketing decisions are inefficient; given the fact that, education would help in intensifying the effectiveness and quality of human activity. Besides, it is this higher illiteracy rate that is responsible to explain the prevailing multidimensional poverty in the area. More than half of the total response rate didn't have access to at least basic education could imply that most household activities are based on non-technical traditional practices. Inefficient decisions reduce labor and other resource productivity as well as the overall product level. Pooreducation may be one of the basic factors to explain their weak economic, political and other dimensional positions. Using figures, we can equivalently analyze the frequency distribution of education among the sample respondents as follows;

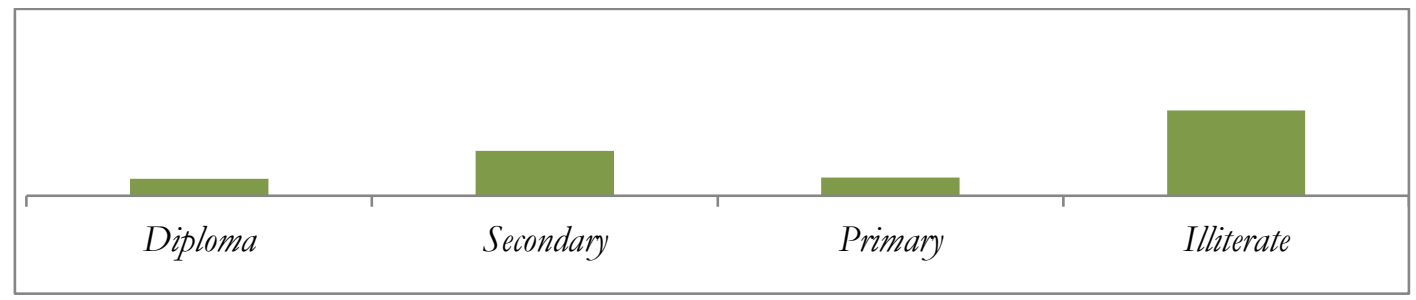

Source: (Own Survey, 2018)

\section{FIGURE 4. EDUCATION PURSUED BY HOUSEHOLDS}

We observe from figure (3) that, the highest room for the illiterate group being followed by those who attended secondary education. Both groups together form about 78.85 percent of the total response rate of which about 65.56 percent are still illiterate. Those who pursued tertiary education account for a very small proportion of the total response rate. Overall, this particular analysis on the frequency distribution of education among the sample household reveals that, majority of the individuals in the study area is illiterate. We could hence infer that, this high illiteracy rate may be a factor that could explain multidimensional poverty and inadequate welfare across households from Jimma zone.

\section{Inferential Analysis}

Prior to the estimation of binary logistic model, we have addressed the necessary validity, consistency and reliability requirements issues with logistic regression. In none of the 
specific cases was the necessity test failed. We present the individual test result in sections below.

Let's first see the model fitness condition. As discussed under methodology section, the goodness-of-fit of the logistic specification can be verified by the reported log likelihood ratio together with the regression coefficients, the score condition and the Wald test. Each test of the overall model strength has proved valid; and hence the inference based on logistic estimates.

TABLE 4. TESTING GLOBAL NULL HYPOTHESIS (HO: $B=0$ )

\begin{tabular}{lrr}
\hline Test List & Chi2 & Pr $>$ Chi2 \\
\hline LL Ratio & 57.4782 & $<.0001$ \\
Score & 59.3547 & $<.0001$ \\
Wald & 52.6925 & $<.0001$ \\
\hline
\end{tabular}

Source: Own Manipulation using STATA ver. 14 (2018)

We see that (table 4), the Likelihood ratio, Score and Wald test statistics are all significant withp-value less than 0.05.This indicates that the final model with explanatory variables included was more effective than a model without explanatory variables. Hence, there is significant relationship between the dependent and set of all independent variables. Moreover, we have examined the Hosmer-Lemeshow condition for the goodness-of-fit of our logistic specification, and confirmed the fulfillment. The Hosmer-Lemeshow test statistic was estimated at $12.65(\mathrm{p}=0.1244)$, which is strongly significant at 5 percent.

With regard to logistic diagnostic issue, we considered DFBETA for each regressor as well as the average term, standard residuals and influential observation issues, and all were tested robust.The Adequacyof fitted model was examined for possible presence and treatment of outliers and influential observation.See table (5) below for the test statistics.

TABLE 5. DIAGNOSTIC TEST RESULTS

\begin{tabular}{lccc}
\hline Test Type & Obs. & Minimum & Maximum \\
\hline Analog of Cook's influence statistics & 383 & $3.30 \mathrm{e}-08$ & 0.0450509 \\
Standard Residual & 383 & -2.110746 & 1.85213 \\
DFBETA for TSSC & 383 & -0.3675358 & 0.1578752 \\
DFBETA for EDUC & 383 & -0.2547097 & 0.3009825 \\
DFBETA for AGE & 383 & -0.2025523 & 0.2216249 \\
DFBETA for IDIR & 383 & -0.1789904 & 0.1874204 \\
\hline
\end{tabular}

Source: own computation using stata ver. 14 (2018)

The DFBETAs for parameters and Cook's influence statistics are both less than unity. DFBETAs of less than unity indicating no specific impact of a given observation on the coefficient of a particular predictor variable; whereas Cook's distance less than one reveals that an observation had no universal effect on vectors of logistic regression coefficients $(\widehat{\beta})$. The normalized residuals were reported to lie within the interval of ( -3 and 3$)$,demonstrating the absence of an outlier in our logistic specification. Consequently, relevant statistical requirements have tested robustness with our logistic specification of this study.

\section{Effect of Social Capital Stock on Household Economy}

Here we aim to examine theimpact of households'aggregate social capital stock on their economic performance, measured by the method briefed so far. As it is quite clear, a 
principal regressor in our logistic specification is social capital stock. The' Idir' dummy accountedby the household civic engagement was another aspect of social capital in the model. Besides, we also control for household heads'number of years of schooling as well as age in years. Our Stata 14 display for logistic manipulation looks a copy below;

TABLE 6. SOCIAL CAPITAL AND HOUSEHOLDECONOMY

\begin{tabular}{lccc}
\hline Regressors & Coeff. & Std. Error & Prob. \\
\hline TSC & 0.311 & 0.050 & 0.000 \\
IDIR & 0.416 & 0.307 & 0.229 \\
AGE & 0.014 & 0.012 & 0.176 \\
EDUC $_{i}$ & 0.150 & 0.041 & 0.000 \\
Log LL Ratio: Chi $^{2}(4)=87.55[0.000]$ & PseudoR $^{2}=0.2125$ & & \\
\hline Saur OunSUne & & \\
\hline
\end{tabular}

Source: Own Survey (2018)

For logit estimate reliability issues, the log likelihood ratio indicating overall relevance of the model is robust thereby ensuring reliability of inferences based on our estimates. Besides, regressors entered the model jointly account for about a quarter of variations in the response variable, signifying the need for consideration of other variables for futurestudies in related topics.

Evident from table (6) is the strongly significant and positive coefficient of household's total stock of social capital on its economic status. Its estimated coefficient being $0.311(0.000)$ signifies that, when an individual households stock of social capital increases by a unit, its odds in favor of economic wellbeing will be intensified by about 0.311 units. Besides, an improvement in the households' total stock of social capital increases the likelihood that an individual household is economically secured. Moreover, the estimated weight of social capital is relatively large thereby further revealing its relevance in the wellbeing of the people. The economic aspect of social capital could be realized as a result of production efficiencies (Nie etal., 1996; Durlauf, 2002; Loury, 1977); decreased transaction costs (Greif, 1993; DiPasquale and Glaeser, 1999); better team work and effects of individual networking (Ball et al., 1998; Putnam, 1995\{2000\}). This finding is theoretically expected and empirically similarto Reimer (2014) in Canada; Reinsberg et al (2013) in Poland; and Terrence (2014) in United States.AnIdirdummy was suggested to have insignificant effect on household economy. The reported differential effect $(0.416)$ was suggested insignificant even at 10 per cent. Thus, there are no real economic differences across households whether or not they are members of their community self-help association called Idir. It means that the dummy for Idir has not been important in explaining the households' economic position. This result may not be surprising from the economic perspective; given that, such associations, like Idir, are mainly targeted for social rather than economic matters. With Idir, individualscome together to share social emergencies and occasional burdens in life.

Education was another relevant consideration. We have estimated a positive $(0.150)$ and statistically significant $(\mathrm{p}=0.000)$ impact of household's education level on its economic position. The coefficient reveals that, a year extra schooling increases odds of household being economically secure by 0.15 , which is statistically significant improvement from the computational point of view. Hence, household economic status has been found to vary 
positively with the level of education attended. Thepositive coefficient of education is obvious. Education affects life adequately; and in respect of economy, education is argued to enhance mechanized production techniques thereby developing knowledge and workers and improving managerial efficiency. All these allow for individual's raising productivity and hence overall product level.

An age variable was also found irrelevant. The estimated coefficient $0.014(0.229)$ reveals that the effect of householder's age is not significant. It indicates that, when the age of a household head increases by a year, the odds of that household being economically secured improves by about 0.014 ; yet insignificant improvement. Theconnotation with this particular case may be that, life experience doesn't matter while economic performanceis considered. In fact, time allows an individual to learn while doing thereby simultaneously providing opportunities to take advantages ofadvancing technology that could enhance easy life. In contrast, if you let your time pass for nothing eventually you will finally end up with added but lost time life. Most of the time, experiences help in business and popularly claimed to contribute positive asset arising from economies of scale due to large size.

In general, the total stock of social capital that a household possess contributes towards improving its economic endeavor. Furthermore, households' status in education was found important in explaining their economic performance. That means, with higher level of education households' perform well in economic regards. But, Idirdummy and the age considerations were irrelevant with reference to household economy.

\section{General versus Special Social Capital: Analysis of Relative Economic Importance}

We took step ahead towards analyzing the relative importance of general and special components of social capital.Here, we examine as to which of the two household economic condition was more responsive. According to social science theories, the special aspect matters more compared to the general aspect, in reference to their multidimensional role in human life. The premise follows that, whether an individual likes or not, general relations are there and no effort from the individual to exist. In contrast, special relations are usually created with large effort, hence interpreted meaningfully. As a result, special aspect of social capital would be tough in human relationships (Ashford, 2005). The later aspect of social capital is more likely intensifying household economic as well as other relevant events, compared to the earlier. In this study, we expect better role of the special aspect of household social capital with reference to Jimma zone. To determine the relative importance, we run logistic regression in two regressors, and the result is displayed below:

TABLE 7. RELATIVE IMPORTANCE OF GENERAL AND SPECIAL CAPITAL ON HOUSEHOLD ECONOMY

\begin{tabular}{lccc}
\hline Regressors & Coef. & Std. Error & $P>|\mathbf{Z}|$ \\
\hline GSC & 0.2796505 & 0.2060365 & 0.175 \\
SSC $_{i}$ & 0.3455757 & 0.0567074 & 0.000 \\
Cons. & $-1.156174(0.000)$ & & \\
LR Chi' $(2)=69.12[0.000]$ Pseudo $R^{2}=0.1678$ & & \\
Response Variable: Dummy for Economic Security0bs. $=383$ & & \\
\hline
\end{tabular}

Note: A value in [ ] is the probability of the log likelihood ratio.

Source: (Own Survey, 2018) 
The validity of two regressor model can be ensured by its significant probability of chi square (table7). Moreover, the reported pseudo-R2value of about 16.78 percent is fairly good for such large cross sectional observation in only two regressors (Wooldridge, 2013; Poulton and Kent, 2008).

Figures in the table describe everything in advance! The special aspect of household social capital is more likely to significantly contribute towards household economic wellbeing (table 7). There is evidence for significant and positive effect of special social capital on household economic security. Our regression result reveals that, when an individual household's special capital stock improves by a unit measure; the odds of economic security will be intensified by about 0.34 ; whereby by granting the likelihood of household economic safety. Thisimprovement in the household's economic position is highly meaningful as the estimated coefficient is strong. Besides, sign of the estimated coefficient was right; and empirically similar to (Ashford, 2005; Reimer, 2002; Reinsberg et al, 2005). The assertion is that, it is the special component of social capital that contributes more to the prosperity of the people. To the other side, households' general social capital has been found not important in their economic considerations. Its estimated coefficient of $0.27(0.175)$ clearly reveals that the general aspect of household social capital has nothing to do withsafeguardingtheir wellbeing. General relationships do not guarantee real interpersonal linkages, exchange of relevantideasand meaningfulinterpretations of those relations; and that might explain why they often ceaseto maintain theindividual as well as group welfare (Uzawa, 2005; Saidov, 2018; Dildar, 2010).

We see that general social capital has nothing to do, unless appropriated meaningfully. Obvious is a positive but insignificant impact from the households' economic wellbeing; whereby the positive coefficient indicating if wise approaches were there for appropriation, it would have had desirable economic signal. In contrast, the role of special social capital in advancing household economy is strongly significant in the expected direction. The implication is straight forward; relations having no meaningful interpretations could end up non-sense.

\section{CONCLUSIONS}

This study established relationships between social capital and economic performance,using household survey from Jimma zone. A prime goal wasestimating the impact of social capital on household economy. There is evidence that, an economic effect of social capital on household economic performance was positive and strongly significant. Separatelogit regression yielded insignificant coefficient for general social capital, demonstrating irrelevant economic value from the general aspect of societal networks in the study area.But, the same regression indicated robust and positive sign for special social capital. Results tell us that, the economic relevance of special social capital was found much higher than the general stock. The implication follows that, though social capital plays obvious role for multifaceted social development, it could have nothing to do unless the share of special aspect is intensified. General social capital, which can be established exogenously without ones 
desire, is not such influential. Animportant experience nowcallsfor schemesto intensifygrowth of special relations even from general ones. Besides, interventions to encouragedevelopments in social capital across households in rural Jimma could support the national program of ensuring food security and maximizing rural welfare.

\section{REFERENCES}

Becker G. (1964): “Human Capital”, Working Paper, National Bureau of Economic Research, Columbia University, New York

Coleman J. (1990): "Foundations of Social Theory", Critical Review Paper, Harvard University Press.

Dasgupta P. (2005): "Economics of Social Capital”, A Review Paper,Journal of Economic Record, 81(225), pp(2-21).

Dayaratne, Wickramasuriya, Somaratne (2011): "Does Social Capital Matter?: Case of Central Province of Sri Lanka”, Agricultural Research Paper, University of Peradeniya.

Dildar Y. (2010): "Social Capital and Economic Development: Critical Review”, Article Review, University of Massachusetts, Amherst

Durlauf S. (2002): "On the Empirics of Social Capital”, Article Review, Economic Policy Review Office

Ferragina E. (2010): "Social Capital and Equality: Rethinking social capital in relation with income inequalities”, Research Review, Revue Tocqueville, 31(1), pp( 73-98).

Glaeser E., and DiPasquale D. (1999): "Incentives and Social Capital: Are Homeowners Better Citizens?”, Research Article in Social Work, Journal of Urban Economics.

Greif A. (1993): "Contract Enforceability and Economic Institutions in Early Trade: the Maghribi Traders' Coalition”, Review Paper, American Economic Review.

Grossman P., Ball C., Eckel C., and Zame W. (2000): "Status in Markets”, Market Survey Analysis, version 62, 2000

Gujarati (2004): "Basic Econometrics", 4th ed., New York, The McGraw-Hill

Keefer P. and Knack S. (1997): "Does Social Capital Have an Economic Pay-off?: A Panel Analysis", Research Paper in Economics, Quarterly Journal of Economics.

Loury G. (1977): “A Dynamic Theory of Racial Income Differences”, Special Print, Lexington Books.

Maskin E. and Fudenberg D. (1986): "The Folk Theorem in Repeated games with Discounting or with Incomplete Information”, Research Paper in Economics, Econometrica.

Organization for Economic and Cultural Development (2009): "Strategies to Improve Rural Service Delivery”, Country Survey, OECD Publishing, Paris, 2009

Organization for Economic and Cultural Development (2013): "Strategies to Improve Rural Service Delivery”, Policy Discussion, OECD Publishing, Paris

Paldam M. (2000): "Social Capital: One or Many? Definition and Measurement”, Article Review, Journal of EconomicSurveys, 14(5), pp(629-653). 
Poulton C. and Kent R. (2008): "Marginal Farmers", Review of the Literature, Center for Development Policy, School of African Studies

Putnam R. (1995): "Bowling Alone: America's Declining Social Capital”, Conference Paper, Journal of Democracy, 6(65-78).

Putnam R. (2000): "Bowling Alone: The Collapse and Revival of American Community", Critical Review Paper, New York, Simon and Schrster.

Saidov SS. (2018): "The Conceptual Analysis of Social Capital within Society", Article Review, Sch J Appl Sci Res, 1(3), pp(71-75).

Sobel J. (2002): “Can We Trust Social Capital”, Research Review, Journal of Economic Literature 40(1), pp(139-154).

Stehlik-Barry K., Nie N., and Junn J. (1996): "Education and Democratic Citizenship in America, Chicago", Special Print, University of Chicago Press.

Stiglitz J. (1999):“Formal and Informal Institutions in Social Capital”, Discussion Paper, pp(59-68), Washington DC, USA: The World Bank.

Thokozani S. (2012): “To What Extent Cities Are Influenced by Rural-Urban Relationships in Africa”, Research Article, Durban University of Technology, South Africa.

UN (2005): "World Urbanization Prospects: the 2004 Review", Literature Review, Economic and Social Affairs Department, New York: United Nations, 2005.

Uphoff N. (1999): "Understanding Social Capital: Learning from the Analysis and Experience of

Participation in Social Capital”, Discussion Paper, pp(215-249), Washington DC, USA

Uzawa H. (2005): "Economic Analysis of Social Common Capital", 1sted., Cambridge University Press

Wickramasuriya, Somaratne and Dayaratne (2011): "Does Social Capital Matter in the Wellbeing of Rural People?: Central Province of Sri Lanka”, Research Paper, University of Peradeniya, Peradeniya.

Wooldridge J.M. (2013), "Introductory Econometrics: A Modern Approach", 5th ed., Michigan State University

Yan Li. and Shufang W. (2010): "Social Ties and Health among Rural-Urban Migrants in China: A Channel or a Constraint?”, Research Article, University of Nottingham. 